\title{
Characterization of a metallic interconnect operated in stack during 40,000 hours in SOFC mode
}

\author{
Paolo Piccardo ${ }^{*}$, Roberto Spotorno ${ }^{1}$, Valeria Bongiorno $^{1}$, Daniele Paravidino ${ }^{1}$, Christian Geipel $^{2}$, Greta Patrone $^{1}$ and \\ Francesca Valente $^{1}$
}

${ }^{1}$ UNIGE Chemistry and Industrial Chemistry Department, 16146 Genoa, Italy

${ }^{2}$ SUNFIRE GmbH, Gasanstaltstraße 2, Dresden, 01237,Germany

\begin{abstract}
An SOFC stack operated for 40,000 hours has been dismantled offering the opportunity to characterize the metallic interconnect. The metal plate was carefully investigated to define the evolution of the surfaces exposed to the air and to the hydrogen electrodes respectively. The observations of the surfaces reveal the stability of the layers applied on top of the rib at the air side while in the bottom of the channels the protective coating (i.e., Co-Mn base spinel oxide) shows large crystals. The cross section allowed to highlight the formation of a rather homogeneous layer of thermal grown oxide between the metal and the coating. The average thickness of the TGO is around $11 \mu \mathrm{m}$. The hydrogen side shows a superficial alteration (due to the interaction with the water vapour) changing from the inlet to the outlet where it seems thinner as if the TGO further reacted by forming volatile compounds. The cross section observations confirmed the presence of a porous TGO with a rather high content of manganese in a Cr-Mn spinel oxide. Several spots testifies the zones of contact with the Ni base contacting layer. The cross section corresponding to such zones highlighted the Ni diffusion in the metal substrate.
\end{abstract}

\section{Introduction}

In the perspective of an efficient decarbonisation of the energy production the usage of hydrogen as fuel for power plants seems to be a logical solution [1] due to its compliance with the renewable power sources (e.g., photovoltaic, wind power) often characterized by the intermittence of operating period and by the need of an energy storage solution. Moreover, the usage of "green hydrogen" would increase the environment friendly characteristic of power plant fuelled by such an energy vector. To reach and sustain such a goal the scientific community is widely engaged to fulfil the few issues still slowing down the trend to the ecological transition demanded by the citizens and by the planet itself.

One of the issues is the durability of the power plant and its reliability on the long lasting period with the corresponding low degradation rate.

Among the possible solutions, the solid oxide fuel cells (SOFC) are favoured for their high efficiency in energy conversion of the reaction between hydrogen and oxygen reaching more than $90 \%$ if heat and electrical power are considered [1]. The operating time needed to make the stack built around SOFCs is at least 50,000 hours even though the ideal time would be 80,000 hours at an operating temperature between $650^{\circ} \mathrm{C}$ and $850^{\circ} \mathrm{C}$ and an optimal fuel consumption of $80 \%$. The evolution of the components inside a stack is strictly related to the efficiency of the whole system and involves materials evolution and the interaction between materials [2-4].
The interconnects, allowing the separation of cells by granting the passage of electrons from the anode to the cathode of the adjacent cell, have a key role in the stack even though they do not participate to the energy production [5-8]. The state of the art combined heat and power (CHP) devices makes use of metallic interconnects (MICs) based on ferritic stainless steel (FSS) for the following reasons: 1) high electrical conductivity; 2) shapability; 3) easiness to seal with the cells to insure the gas tightness between the cathode and anode chamber; 4) coefficient of thermal expansion (CTE) matching with the one of the cell (especially of the electrolyte); 5) high mechanical resistance; 6) chemical stability obtained by the formation of electrically conductive oxide at the air side eventually enhanced with the application of protective coatings [9]; 7) cost effectiveness.

The reliability of the MICs is fundamental to offer trustworthy power plants, this is due to the delicate and multiple roles they play in the stack and by the direct interaction they have with the cell's electrodes. The usage of FSS rich in $\mathrm{Cr}$ and poor in all other elements to obtain the correct CTE and conductive thermally grown oxide (TGO) makes the presence of coating at the air side mandatory to hinder the formation of volatile compounds rich in oxidized $\mathrm{Cr}$. This is know as one of the most detrimental phenomenon by the rapid poisoning of the cathode three phase boundaries. The coating has the double role to keep the TGO stable in oxidizing atmospheres and to avoid its direct interaction with the

\footnotetext{
* Corresponding author: author@e-mail.org
} 
cathode material to hinder the interdiffusion of cations between the electrode and the oxidized scale $[10,11]$.

Due to the high quality of the FSS used for the MICs the investigations need extremely long lasting experiments to have a correct vision of the phenomena and the reproduction of "real-life conditions" (i.e., temperature, atmospheres, materials). The validation of laboratory tests and the refining of degradation models can only occur by the comparison with components extracted from operated stacks [12-14]. The project Ad Astra offers such an opportunity SOFC stacks field operated for several thousand hours.

The present paper refers on the first results obtained by the post-mortem characterization of MIC samples extracted by a stack field operated for 40,000 hours in fuel cell mode and is an update of previous publications $[12,13]$ referring of interconnects operated for up to 20,000 hours. The results are of fundamental importance for the modelling of the stack performances evolution and for a better understanding of samples issued by accelerated tests.

\subsection{Materials and methods}

The MIC was extracted by an SOFC stack manufactured and operated by Sunfire company (Sunfire $\mathrm{GmbH}$, Dresden, Germany) according to the disclosable working conditions listed in table 1 .

Table 1. Operating parameters for the stack.

\begin{tabular}{|c|c|}
\hline $\begin{array}{c}\text { Operation } \\
\text { type }\end{array}$ & $\begin{array}{c}\text { SOFC } \\
(\mu \mathrm{CHP}), \text { field }\end{array}$ \\
\hline $\begin{array}{c}\text { Total } \\
\text { runtime/h }\end{array}$ & 40,000 \\
\hline $\begin{array}{r}\text { Fuel gas } \\
\text { (Co-flow) }\end{array}$ & $\begin{array}{l}44 \% \mathrm{~N}_{2} \\
34 \% \mathrm{H}_{2} \\
16 \% \mathrm{CO} \\
4 \% \mathrm{H}_{2} \mathrm{O} \\
2 \% \mathrm{CO}_{2}\end{array}$ \\
\hline $\begin{array}{c}\text { Nominal } \\
\text { temperatu } \\
\text { re } /{ }^{\circ} \mathrm{C}\end{array}$ & 850 \\
\hline $\begin{array}{c}\text { Current } \\
\text { density/m } \\
\mathbf{A} \cdot \mathrm{cm}^{-2}\end{array}$ & $90-200$ \\
\hline
\end{tabular}

The major changes expected from inlet to outlet are the temperature gradient common to both side and the composition of the fuel stream with an increase of $\mathrm{pH} 2 \mathrm{O}$ at the fuel side only. The stacks manufactured according to the company standards used electrolyte supported cells based on 3 YSZ as electrolyte, with electrodes made of LSM (cathode) coated with a cathode contacting paste (LSCM on the ribs only) and $\mathrm{Ni}$ cermet (anode) connected to the MIC by a Ni metal foam. The MIC was an undulated plate of ferritic stainless steel CROFER 22 APUC, commercial grade (table 2), joined to the cell electrolyte by a proprietary glass-ceramic compliant sealant. It was coated at the air side only with a manganese cobalt spinel oxide (MCO) doped with Fe.

Table 2. Crofer22APU Chemical composition (wt.-\%) according to the ThyssenKrupp datasheet [15].

\begin{tabular}{|c|c|c|c|c|c|c|c|c|}
\hline $\begin{array}{c}\text { Wt. } \\
\%\end{array}$ & $\mathrm{Cr}$ & $\mathrm{Fe}$ & $\mathrm{C}$ & $\mathrm{Mn}$ & $\mathrm{Si}$ & $\mathrm{Ti}$ & $\mathrm{La}$ & others \\
\hline min. & 20.0 & bal. & & 0.30 & & 0.03 & 0.04 & \multirow{2}{*}{$\mathrm{Cu} \mathrm{Al}$} \\
\hline max. & 24.0 & & 0.03 & 0.80 & 0.50 & 0.20 & 0.20 & \\
\hline
\end{tabular}

The MCO protective coating covers the whole surface following the ribs/channels profile with a constant thickness; it was applied on the bare metal with an initial porosity and Fe content unknown due to the proprietary application method.

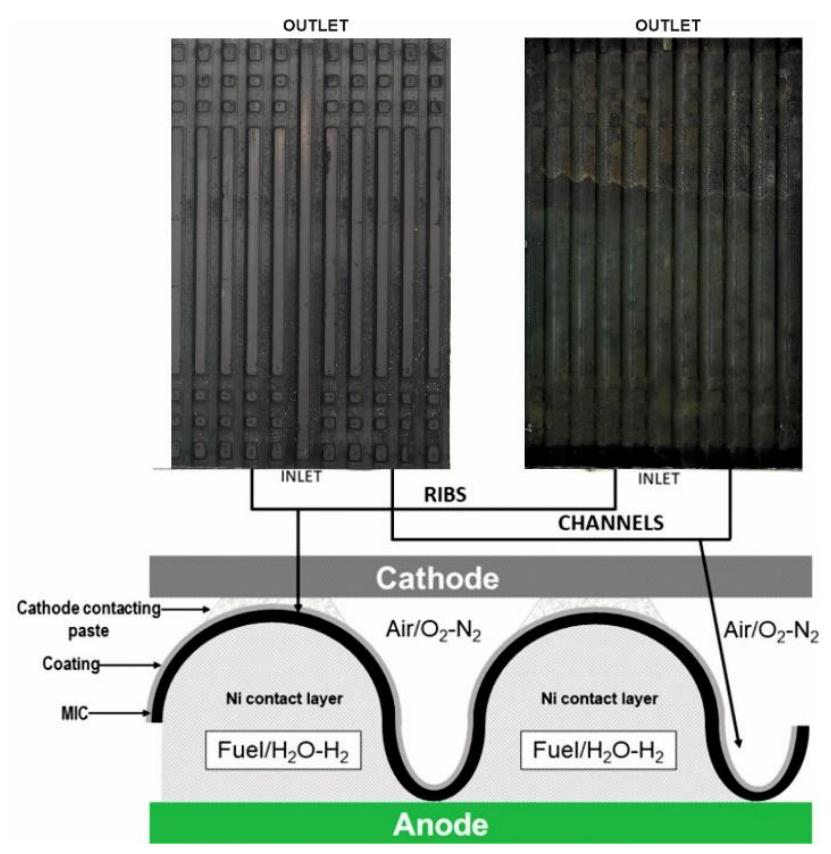

Fig. 1. schematic representation of the MIC cross section and overall vision of the air side (top left) and of the fuel side (top right) with the INLET-OUTLET positions to indicate the co-flow direction of the streaming.

To simplify the identification of the investigated areas on the MIC cross sections, two main positions are conventionally defined: the Ribs, as the part of the plate in contact with the cathode, and the Channels allowing the air flow from inlet to outlet. The air side is contacted with the cathode only by the ribs while at the anode side the whole surface is contacted with the electrode by a porous and compliant $\mathrm{Ni}$ layer. At this side therefore there is no distinction between rib and channel. According to the company information on the field operations from Inlet to Outlet the temperature range passes from ca. $1000 \mathrm{~K}$ to ca. $1050 \mathrm{~K}$ with consequences on the MIC reactivity. The interconnect was therefore divided in four samples all along the flow stream covering nearly $25 \mathrm{~mm}$ of length each sample: inlet, center-inlet, center-outlet, outlet. Each samples was mounted in epoxy resin and polished up to a diamond suspension with $250 \mathrm{~nm}$ of granulometry, to expose the cross section for investigations by a scanning electron 
microscopy (SEM) coupled with an energy dispersive Xray spectroscopy (EDS) calibrated with pure Co reference. The EDS data are treated by INCA software (Oxford) with ZAF 5 correction to achieve quantitative information on metals and semiquantitative data on oxygen.

\section{Results and discussion}

From the characterization of the surface, it results that the fuel side is more affected by the interaction with the gas stream (fig. 1). The $\mathrm{H} 2 / \mathrm{H} 2 \mathrm{O}$ gradient is constantly evolving from the Inlet zone toward the Outlet zone with an increase of water vapour corresponding to a reduction of the hydrogen partial pressure. As already discussed in [12] the oxidation of the MIC is due to the interaction with the water vapour and corresponds to the formation of a TGO rich in $\mathrm{Mn}$ and $\mathrm{Cr}$ evolving into a $\mathrm{Mn}$ richer oxidized layer by the evaporation of $\mathrm{Cr}$ rich volatile compounds. The overall electrical conductivity is not affected by the TGO formation due to the numerous zones of welding between the Ni contacting layer and the MIC as visible in figure 2. Such zones corresponds to the interdiffusion between $\mathrm{Ni}$ and FSS forming an intermediate alloy rich in $\mathrm{Ni}$. The cross section allowed finding a wide diffusion zone of $\mathrm{Ni}$ in correspondence of the spot welding area. In this zone, coherently with the Cr-Fe-Ni phase diagram [16], a second phase rich in $\mathrm{Cr}$ separated from the main matrix. Such phases present several cracks probably due to the compressive stress applied by the surrounding alloy that has a higher CTE due to the presence of $\mathrm{Ni}$.

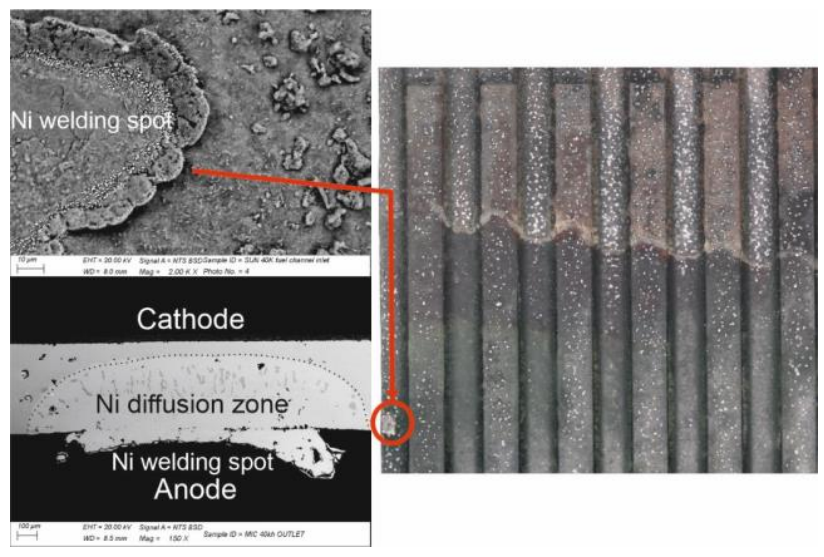

Fig. 2. Fuel side, OUTLET zone, visible welding spot of the Ni contacting layer with the anode

The remaining surface of the MIC at the fuel side presents various form of oxide with, in the central zone between the inlet and the outlet, evidence of the presence of conglomerates interpreted as bubbles once observed in cross section (fig. 3). This morphology is typically related to the formation of volatile compounds by the further oxidation in presence of water vapour of $\mathrm{Cr}$ rich oxides. The remaining scale covering the mic shows a micro porosity matching with the evaporation phenomenon.

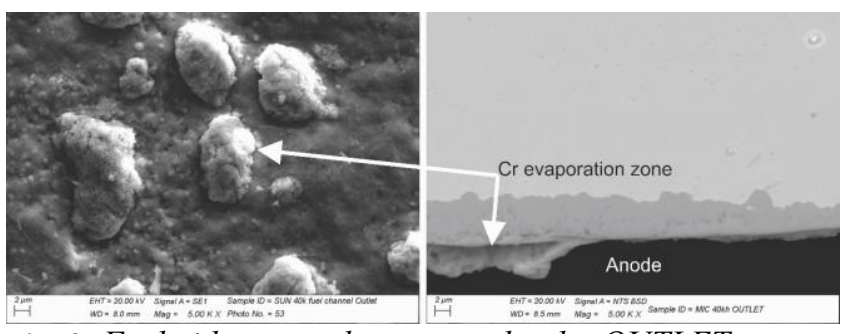

Fig. 3. Fuel side, central area nearby the OUTLET zone, superficial bubbles with detail in cross section showing the cavity due to volatile compounds

At the air side the macroscopic observation shows only the presence of large crystals in the ribs, where the air stream flows without obstacles from the inlet to the outlet zones. In figure 4 a detail on such crystals is presented. They formed on top of the MCO coating and correspond to spinel oxide where $\mathrm{Cr}$ is trapped. The MCO in cross section appears well adherent to the metal substrate and with a remaining porosity despite the 40,000 hours at high temperature. The TGO formed at the interface with the FSS.

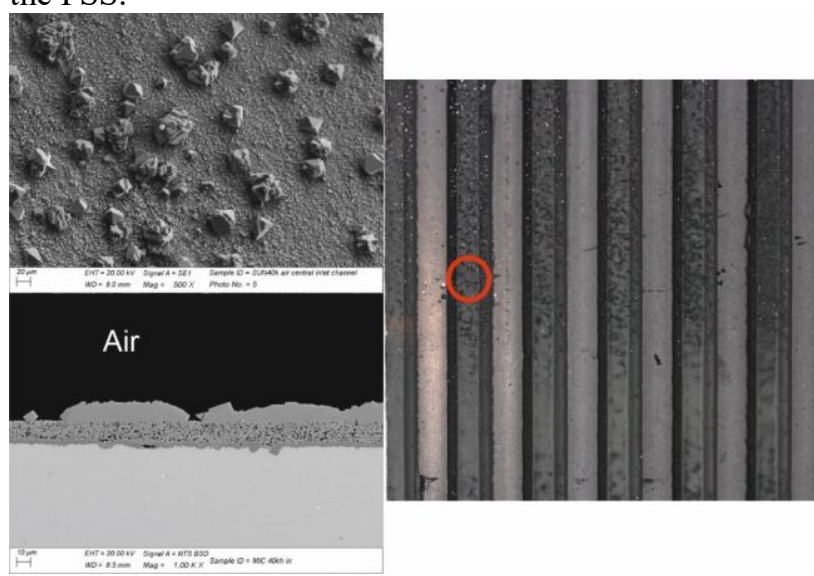

Fig. 4. Air side, central area inside a channel with large spinel crystals containing $\mathrm{Mn}, \mathrm{Co}, \mathrm{Cr}, \mathrm{Fe}$ on top of the MCO coating. Details are visible on the cross section image

In figure 5 a representative image of the situation found on the rib (i.e., where the cathode enters in direct contact with the interconnect) is presented. The surface shows the homogeneous presence of crystals of contacting layer with a possible increase of the crystals size to be discussed more in details after further studies. The cross section reveals the presence of multiple interphases related to the interaction between the various layers. The contacting layer and the MCO coating have sporadic interactions with formation of dense phases but, in general, $\mathrm{Cr}$ remains in the coating where it enters by solid-state diffusion. The TGO formed at the interface with the MIC is mainly due to the diffusion of oxygen from the coating. This limits the TGO growth rate as results by table 3 with related graphic (fig. 6).

The TGO thickness increases on both sides but it results definitely thicker at the fuel side due to the absence of protective coating. The range of thickness observed from the inlet to the outlet is related to the differences in temperature (i.e., up to $60 \mathrm{~K}$ ) between the two zones and, for the fuel side only, by the change in favour of the 
water vapour of the ratio $\mathrm{H} 2 / \mathrm{H} 2 \mathrm{O}$ due to the anodic reaction.
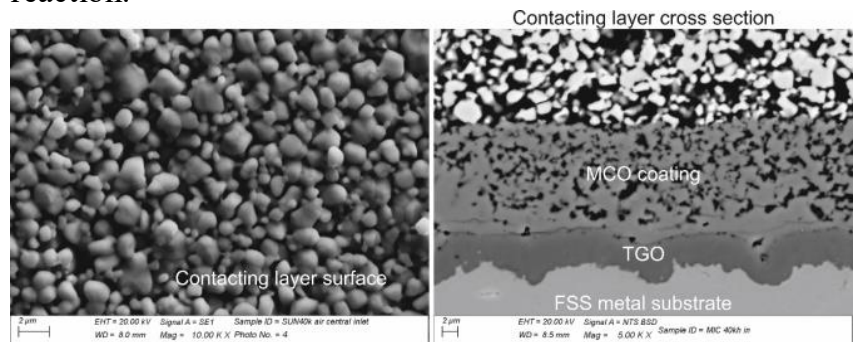

Fig. 5. Air side, central area on top of a rib (surface view) and related cross section with all visible interphases from the metal substrate to the top contacting layer

\begin{tabular}{|c|c|c|c|c|}
\hline & $\begin{array}{c}\text { TGO fuel } \\
\min (\mathrm{mm})\end{array}$ & $\begin{array}{c}\text { TGO fuel } \\
\max \\
(\mathrm{mm})\end{array}$ & $\begin{array}{c}\text { TGO air } \\
\min (\mathrm{mm})\end{array}$ & $\begin{array}{c}\text { TGO air } \\
\max \\
(\mathrm{mm})\end{array}$ \\
\hline $\begin{array}{c}\text { inlet } 0- \\
2.5 \mathrm{~cm}\end{array}$ & 6 & 8 & 2 & 5 \\
\hline $\begin{array}{c}\text { center-in } \\
2.5-5 \mathrm{~cm}\end{array}$ & 3 & 9 & 4 & 11 \\
\hline $\begin{array}{c}\text { center-out } \\
5-7.5 \mathrm{~cm}\end{array}$ & 7 & 18 & 4 & 14 \\
\hline $\begin{array}{c}\text { outlet } \\
7.5-10 \mathrm{~cm}\end{array}$ & 10 & 24 & 9 & 17 \\
\hline
\end{tabular}

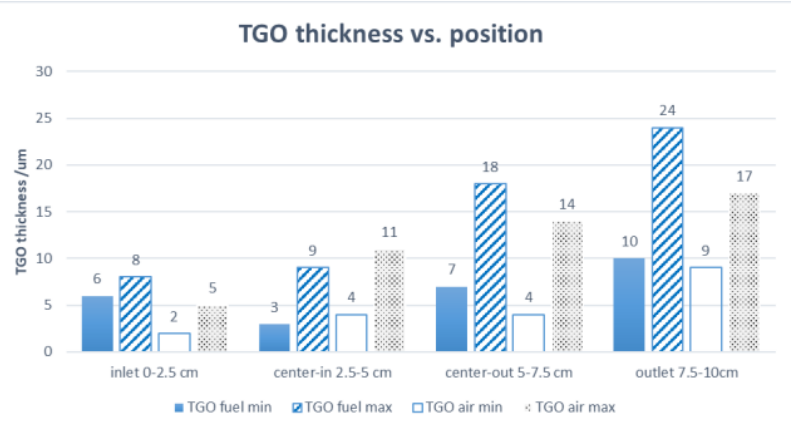

Fig. 6. Graphic representation of the TGO thickness range at the fuel and air side respectively

\section{Conclusions}

The rare opportunity to characterize components operated for a very long period allowed the investigation on a metallic interconnect extracted from an SOFC stack field operated for 40,000 hours. The preliminary results has shown the following highlights on the materials evolution:

1) The fuel side results more affected by the interaction with the gas stream than the air side

2) The protective coating confirms its efficiency on the long lasting period by gathering the $\mathrm{Cr}$ moving by solidstate diffusion from the metal substrate.

3) The MIC in contact with the cathode shows an evolution by the formation of a TGO with a growth rate depending by the temperature (which confirms to be an important accelerator of such an ageing process)
4) The fuel side of the MIC presents various form of oxidation with the evidence of $\mathrm{Cr}$ evaporation. The TGO grows faster than at the air-side but without affecting the electrons exchange between the anode and the MIC. This is due to the formation of welded spots between the MIC and the Ni contacting layer

5) In correspondence of the welded spots the MIC changes locally the composition with a remarkable increase of the $\mathrm{Ni}$ content provoking the formation of a differing alloy with the precipitation of hard and brittle second phase rich in $\mathrm{Cr}$.

As general conclusion it is possible to suggest that the MIC observed has maintained a sufficiently satisfying functionality even after 40,000 hours of operation. However, the diffusion of Ni into the FSS matrix, which is locally transformed into an austenitic alloy with $\mathrm{Cr}$ rich large precipitates, and the thick TGO formed on both sides (i.e., air and fuel side respectively) are clear warning signals that some counterstrategies should be applied to reach the planned 80,000 hours for the next generation SOFC stacks.

Temperature and water vapour partial pressure confirm their key role as accelerating parameters of the ageing phenomena related to the MIC. The design of accelerated tests should take these and the previous results into account to better understand how to use the accelerating parameters to perform meaningful laboratory experiments.

The research leading to these results has received funding from the Fuel Cells and Hydrogen 2 Joint Undertaking under Grant Agreement No 825027.

\section{References}

Here are some examples:

1. J.B. Hansen, Faraday Discuss, 182 (2015)

2. Michael C. Tucker, Int. J. Hydrogen Energy, in press

3. Y. Yan, Q. Fang, L. Blum, W. Lehnert, Electrochimica Acta 258 (2017)

4. C. Chatzichristodoulou, M. Chen, P.V. Hendriksen, T. Jacobsen, M.B. Mogensen, Electrochimica Acta 189 (2016)

5. D. The, S. Grieshammer, M. Schroeder, M. Martin, M. Al Daroukh, F. Tietz, J. Schefold, A. Brisse, Journal of Power Sources 275 (2015)

6. M. Riedel, M. P. Heddrich, K. A. Friedrich, Int. J. Hydrogen Energy 22 (2019)

7. Regis Anghilante, David Colomar, Annabelle Brisse, Mathieu Marrony, Int. J. Hydrogen Energy 4345 (2018)

8. Juhyun Yoo, Sang-Kuk Woo, Ji Heng Yu, Siwoo Lee, Gun Woo Park, Int. J. Hydrogen Energy 343 (2009) 
9. Xiaoyu Zhanga, James E. O'Brien, Robert C. O'Brien, Joseph J. Hartvigsen, Greg Tao, Gregory K. Housley, Int. J. Hydrogen Energy, 381 (2013)

10. M.R. Ardigò, I. Popa, S. Chevalier, P. Girardon, F. Perry, R. Laucournet, A. Brevet, C. Desgranges, Int J. Hydrogen Energy 3936 (2014)

11. M. Bianco, J.P. Ouweltjes, J. Van herle, Int. J. Hydrogen Energy 4459 (2019)

12. G. Ghiara, P. Piccardo, V. Bongiorno, L. Repetto, C. Geipel, R. Spotorno, Int. J. Hydrogen Energy, 46 (2021)

13. G. Ghiara, P. Piccardo, V. Bongiorno, C. Geipel, R. Spotorno, Energies 13 (2020)
14. M. Bianco, P. Caliandro, S. Diethelm, S. Yang, A. Dellai, R. Steinberger-Wilckens, Journal of Power Sources, 461 (2020)

15. ThyssenKrupp VDM, Crofer 22 APU - Material, Data Sheet No. 4046 (2010)

I. Ansara, T. G. Chart, P.Y. Chevalier, Phase diagrams for FE-CR-NI based alloys, CDNA-09-657-EN-C (1996) 